\title{
Mononuclear Leukocyte Apoptosis and Inflammatory Markers in Patients with Chronic Kidney Disease
}

\author{
Evangelia Dounousi $^{\mathrm{a}} \quad$ Elli Koliousi $^{\mathrm{a}}$ Aikaterini Papagianni $^{\mathrm{b}}$ Kyriakos loannou $^{\mathrm{d}}$ \\ Xanthi Zikou $^{\text {a }}$ Konstantinos Katopodis $^{a}$ Apostolos Kelesidis ${ }^{d}$ \\ Dimitrios Tsakiris $^{c}$ Kostas C. Siamopoulos ${ }^{a}$ \\ Departments of Nephrology of a University Hospital of loannina, loannina, ${ }^{b}$ General Hospital of Thessaloniki \\ 'Hippokration', 'General Hospital of Thessaloniki 'Papageorgiou', Thessaloniki, and d General Hospital of Veria, \\ Veria, Greece
}

\section{Key Words}

Apoptosis · Inflammation $\cdot$ Chronic kidney disease

\begin{abstract}
Background/Aim: Increased apoptosis along with enhanced inflammation has been reported in hemodialysis and predialysis patients. However, there is limited information at which stage during the progression of chronic kidney disease (CKD) the balance between pro- and anti-apoptotic mechanisms is disturbed and inflammatory response is activated. The aim of this study was to investigate possible alterations in apoptotic and inflammatory markers during CKD (stages 1-4) progression and the probable interactions between them. Methods: In a cross-sectional study, 152 steadystate CKD outpatients ( 83 males, $55 \%$ ) with mean estimated glomerular filtration rate $46(29-76) \mathrm{ml} / \mathrm{min} / 1.73 \mathrm{~m}^{2}$ were studied. Apoptosis was assessed in peripheral blood mononuclear cells by estimating $\mathrm{Bcl}-2$ expression, annexin V-propidium iodine staining and serum soluble Fas (sFas) and Fasligand. Serum levels of C-reactive protein, tumor necrosis factor- $\alpha$ (TNF- $\alpha)$, interleukin- 6 and plasma levels of fibrinogen were measured as markers of inflammation. Results: $\mathrm{BCl}-2$ expression was found to decrease significantly in both
\end{abstract}

lymphocytes and monocytes from CKD stage 1 to 4 . In contrast, the activity of sFas increased significantly and so did the levels of TNF- $\alpha$ and fibrinogen. The majority of these alterations occurred as soon as patients entered stage 3 of CKD. A multivariate regression analysis demonstrated that CKD remained a significant predictor of the aggregate of the assessed markers. Conclusions: Apoptosis appeared to increase across CKD stages 1-4, and this was associated with increased proinflammatory activity.

Copyright $\odot 2012$ S. Karger AG, Basel

\section{Introduction}

Increased apoptosis of leukocytes has been described in hemodialysis (HD) and non-dialysis patients, while miscellaneous factors, such as, uremia, acidosis, oxidative stress, iron overload and malnutrition have been implicated [1-3]. In addition, a significant percentage of $\mathrm{HD}$ patients demonstrate an activated inflammatory response in the absence of any apparent cause $[4,5]$. Apoptosis and especially inflammation are established nontraditional, uremia-related cardiovascular risk factors implicated in the high incidence of cardiovascular mor-

\section{KARGER}

Fax +4161306 1234 E-Mail karger@karger.ch www.karger.com

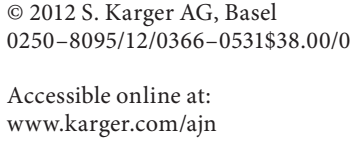


bidity and mortality in chronic kidney disease (CKD) patients [5]. However, there is limited information at which stage during the progression of CKD the balance between pro- and anti-apoptotic mechanisms is disturbed and inflammatory response is activated.

The aim of the study was to investigate possible alterations in apoptotic and inflammatory markers along with CKD stage 1-4 progression, the exact time in the course of CKD when these disturbances occurred and the probable interactions between them.

\section{Subjects and Methods}

\section{Patients}

One hundred and fifty-two successive CKD stage 1-4 patients (83 men, 55\%) with a mean age of 62 years (range $28-88$ ) were enrolled from two renal outpatient clinics. Primary renal diseases were hypertensive nephrosclerosis in 23 patients (15\%), diabetic nephropathy (biopsy proven) in 18 (12\%), chronic glomerulonephritis in 27 (18\%), interstitial nephropathy in $19(13 \%)$, polycystic kidney disease in 8 (5\%), miscellaneous in 19 (12\%) and unknown in 38 patients $(25 \%)$.

\section{Methods}

Renal function was assessed by measuring estimated glomerular filtration rate (eGFR) using the Modification of Diet in Renal Disease formula [6]. Patient exclusion criteria were acute or chronic infection, active immunologic disease, malignancy, heart failure NYHA stage IV and recent major cardiovascular event, defined as stroke (ischemic or hemorrhagic), angina, myocardial infarction, requirement of coronary intervention and acute limp ischemia during the last 2 months. None of the patients was receiving immunosuppressive drugs at the time of the study.

Study protocol included recording of the demographic characteristics, smoking habits, body mass index (BMI), measurement of blood pressure (BP), comorbidity [hypertension, diabetes mellitus (DM), cardiovascular disease (CVD)] and medications. BP control was defined as $130 \mathrm{~mm} \mathrm{Hg}$ or lower for systolic and $80 \mathrm{~mm} \mathrm{Hg}$ or lower for diastolic BP. A full hematologic and biochemical screening was performed at recruitment. All blood samples were drawn after an overnight fasting. Serum biochemistry was determined using an automated analyzer (Olympus AU580). Intact parathormone (iPTH) was measured with an N-IRMA. C-reactive protein (CRP) was measured by immunoturbidimetry (Integra 800, Roche), and plasma fibrinogen levels were measured by visual agglutination (Thrombolyzer Biomerieux). Urine protein excretion was measured in a 24-hour urine sample (Olympus AU580).

The study was approved by the local ethical committee, and patients participated in the study after being informed and having signed a formal consent form.

\section{Peripheral Blood Mononuclear Cell Apoptosis}

Apoptosis was assessed in peripheral blood mononuclear cells (lymphocytes and monocytes) at recruitment by measuring Bcl-2 expression, annexin $\mathrm{V}$ and propidium iodine (PI) staining using flow cytometry.

\section{Bcl-2 Expression}

A 3-ml blood sample infused in an EDTA vial was incubated at room temperature for 20-24 h without adding culture medium. Erythrocytes were removed by adding $2 \mathrm{ml}$ erythrocyte lysis solution. After $10 \mathrm{~min}$, the sample was centrifuged, washed with phosphate-buffered saline (PBS) and resuspended in $500 \mu$ l permeabilization solution. After 15-min incubation in the dark, the sample was washed and $10 \mu \mathrm{l} \mathrm{Bcl-2-PE} \mathrm{QuantiBRITE}{ }^{\circledR}$ (1:1; Becton Dickinson) were added to the cells. The samples were incubated for $20 \mathrm{~min}$ in the dark, washed with PBS and finally resuspended with $500 \mu \mathrm{l}$ PBS.

The quantitative expression of Bcl-2 was calculated by QuantiCALC ${ }^{\circledR}$, an analysis software that enables visualization of flow cytometry data in terms of antibodies bound per cell (molecules/ cell) [7]. Bcl-2 binding to the cells was expressed as antibodies/cell in three zones: high, medium and low. The median value of the medium zone was used for the analysis, since about $90 \%$ of the positive cells were found in this area.

\section{Annexin V - PI Staining}

Annexin $\mathrm{V}$ detects phosphatidylserine expression on the outer surface of cells during the early apoptotic phase [8]. Once isolated from blood samples anticoagulated with citrate, peripheral blood mononuclear cells were washed with PBS, and density was adjusted to $1 \times 10^{6}$ cells/ml. $5 \mu \mathrm{l}$ annexin V-FITC (fluorescein isothiocyanate) and $10 \mu \mathrm{l}$ of PI stock solution were added to $100 \mu \mathrm{l}$ of cell suspension. After 15 min of incubation in the dark at room temperature, cells were washed and resuspended in $400 \mu \mathrm{l}$ permeabilization solution. The following controls were used: unstained cells, cells stained with annexin V-FITC (no PI) and cells stained with PI (no annexin-FITC). Cells staining positive for PI were considered as dead cells (necrosis or late apoptosis), cells staining positive only for annexin $\mathrm{V}$ were considered as apoptotic (annexin V-FITC+/PI-), and cells negative for both were considered as viable. Cell viability was assessed $1 \mathrm{~h}$ after preparation of samples and expressed as percentage of positive apoptotic cells (FACScan flow cytometry instrument).

Serum Markers of Apoptosis and Inflammation

Serum levels of soluble Fas (sFas), Fas ligand (sFasL), tumor necrosis factor- $\alpha$ (TNF- $\alpha$ ) and interleukin-6 (IL-6) were measured by ELISA using commercially available kits (Quantikine Research and Diagnostic Systems Europe Ltd, Abington, UK). Serum samples were separated from clotted blood by immediate centrifugation $(3,000 \mathrm{~g}$ for $10 \mathrm{~min}$ for sFas, sFasL and IL-6; $1,500 \mathrm{~g}$ for $10 \mathrm{~min}$ for TNF- $\alpha$ ) and stored at $-80^{\circ} \mathrm{C}$ until assay. For sFas and sFasL, sera were diluted 1:10 for quantification of both parameters, and were not diluted for the estimation of TNF- $\alpha$ and IL-6. The sensitivity of the ELISA system was $<30$ and $20 \mathrm{pg} / \mathrm{ml}$ for $s F a s$ and $s F a s L$, respectively, and $0.5 \mathrm{pg} / \mathrm{ml}$ for TNF- $\alpha$ and IL6 . The concentrations of these molecules were calculated by reference to standard curves performed with the corresponding recombinant molecule. All serum samples were tested in duplicate.

\section{Statistical Analysis}

Continuous variables were expressed as mean \pm standard deviation or median with interquartile range. $\chi^{2}$ or Fisher's exact test was used for categorical variables, whereas comparisons of means among the 4 CKD stages were analyzed using one-way analysis of variance and Kruskal-Wallis test as appropriate. Variables exam- 
Table 1. Demographic and clinical characteristics, eGFR, comorbidity and treatment, hematological and biochemical parameters of the study population

\begin{tabular}{|c|c|c|c|c|c|c|}
\hline & $\begin{array}{l}\text { All patients } \\
(\mathrm{n}=152)\end{array}$ & $\begin{array}{l}\text { CKD 1 } \\
(n=19)\end{array}$ & $\begin{array}{l}\text { CKD } 2 \\
(n=39)\end{array}$ & $\begin{array}{l}\text { CKD } 3 \\
(n=54)\end{array}$ & $\begin{array}{l}\text { CKD } 4 \\
(n=40)\end{array}$ & $\mathrm{p}$ \\
\hline Males, \% & $83(55)$ & $8(42)$ & $21(54)$ & $33(61)$ & $21(53)$ & NS \\
\hline Age, years & $64 \pm 12$ & $58 \pm 11$ & $63 \pm 10$ & $65 \pm 13$ & $68 \pm 11$ & $<0.05$ \\
\hline $\mathrm{eGFR}, \mathrm{ml} / \mathrm{min} / 1.73 \mathrm{~m}^{2}$ & $46(29-76)$ & $106(94-118)$ & $75(69-81)$ & $42(36-49)$ & $22(19-27)$ & $<0.001$ \\
\hline BMI & $29 \pm 5$ & $30 \pm 4$ & $29 \pm 5$ & $29 \pm 5$ & $29 \pm 5$ & NS \\
\hline Current smokers, \% & $40(26)$ & $4(21)$ & $8(21)$ & $15(28)$ & $13(33)$ & NS \\
\hline Hypertension, $\%$ & $136(90)$ & $17(90)$ & $33(85)$ & $50(93)$ & $36(90)$ & NS \\
\hline Mean BP, mm Hg & $100 \pm 11$ & $96 \pm 10$ & $101 \pm 11$ & $100 \pm 15$ & $101 \pm 15$ & NS \\
\hline Pulse BP, mm Hg & $57(46-70)$ & $55(40-65)$ & $50(40-64)$ & $60(50-70)$ & $63(50-82)$ & 0.006 \\
\hline BP control, \% & $52(34)$ & $9(47)$ & $11(28)$ & $18(33)$ & $14(35)$ & NS \\
\hline $\mathrm{DM}, \%$ & $45(30)$ & $9(48)$ & $6(15)$ & $18(33)$ & $12(30)$ & NS \\
\hline CVD, \% & $40(26)$ & $4(21)$ & $7(18)$ & $16(30)$ & $13(32)$ & NS \\
\hline RAA blockers, $\%$ & $92(61)$ & $14(74)$ & $25(64)$ & $34(63)$ & $19(48)$ & NS \\
\hline Statins, \% & $55(36)$ & $9(48)$ & $13(33)$ & $18(33)$ & $15(38)$ & NS \\
\hline $\mathrm{EPO}, \%$ & $12(8)$ & 0 & $1(3)$ & $3(6)$ & $8(20)$ & 0.009 \\
\hline $\mathrm{Hb}, \mathrm{g} / \mathrm{dl}$ & $13.2 \pm 1.6$ & $13.8 \pm 1.2$ & $14.2 \pm 1.1$ & $13.2 \pm 1.7$ & $12 \pm 1.3$ & $<0.001$ \\
\hline Total protein, g/dl & $7.3 \pm 0.5$ & $7.4 \pm 0.4$ & $7.3 \pm 0.4$ & $7.4 \pm 0.5$ & $7.2 \pm 0.5$ & NS \\
\hline Albumin, g/dl & $4.2(4.1-4.4)$ & $4.3(4.1-4.4)$ & $4.2(4.0-4.5)$ & $4.2(4.1-4.4)$ & $4.2(4.0-4.4)$ & NS \\
\hline Urine protein, $\mathrm{mg} / 24 \mathrm{~h}$ & $260(130-920)$ & $176(108-3,640)$ & $145(99-212)$ & $251(130-497)$ & $960(418-2,135)$ & $<0.001$ \\
\hline $\mathrm{Ca}^{2+} \times \mathrm{PO}_{4}^{-}, \mathrm{mg}^{2} / \mathrm{dl}^{2}$ & $32.3 \pm 6.2$ & $31.2 \pm 4.9$ & $30.9 \pm 5.4$ & $31.7 \pm 6.6$ & $35.2 \pm 6.3$ & 0.008 \\
\hline $\mathrm{iPTH}, \mathrm{pg} / \mathrm{ml}$ & $71(47-115)$ & $47(32-55)$ & $53(37-90)$ & $63(47-112)$ & $124(99-190)$ & $<0.001$ \\
\hline Cholesterol, mg/dl & $212 \pm 44$ & $201 \pm 30$ & $215 \pm 39$ & $214 \pm 45$ & $212 \pm 54$ & NS \\
\hline Triglycerides, mg/dl & $154 \pm 77$ & $132 \pm 63$ & $141 \pm 63$ & $157 \pm 88$ & $175 \pm 74$ & NS \\
\hline Uric acid, $\mathrm{mg} / \mathrm{dl}$ & $6.5 \pm 1.8$ & $5.5 \pm 1.5$ & $5.5 \pm 1.4$ & $7.2 \pm 1.9$ & $7 \pm 1.6$ & $<0.001$ \\
\hline
\end{tabular}

ined included gender, age, smoking, BMI, mean BP, pulse pressure, $\mathrm{BP}$ control, DM and history of CVD, hemoglobin $(\mathrm{Hb})$, serum total protein, serum albumin, 24-hour urine protein, uric acid, calciumphosphate product, iPTH, total cholesterol, triglycerides, CRP, IL6 , treatment with agents blocking the renin-angiotensin axis (RAA blockers), statins and EPO. Factors with $\mathrm{p}<0.05$ in univariate analyses (for online suppl. table see www.karger.com/doi/000345352) entered a multivariate linear regression analysis, while outcome parameters [Bcl-2 monocytes median (Bcl-2MMed), Bcl-2 lymphocytes median (Bcl-2LMed), sFas, TNF- $\alpha$, fibrinogen] were logtransformed before entering the model. The significance of interactions between variables was tested as well. A p $<0.05$ was considered statistically significant. Statistical analyses were performed using SPSS 17.0 (SPSS, Chicago, Ill., USA) statistical software.

\section{Results}

The distribution of patients in the 4 CKD stages, eGFR, demographic and somatometric characteristics, comorbidity and treatment, hematological and biochemical parameters are presented in table 1 . The median eGFR was $46(29-76) \mathrm{ml} / \mathrm{min} / 1.73 \mathrm{~m}^{2}$. There were significant differences in age $(p<0.05)$ and pulse pressure $(p=0.006)$ across the 4 CKD stages. Hemoglobin was lower, and $\mathrm{Ca}^{2+}$ $\times \mathrm{PO}_{4}{ }^{-}$product was higher in stage 4 compared with the other stages $(\mathrm{p}<0.001, \mathrm{p}=0.008)$. Urine protein, PTH and uric acid increased significantly from CKD stage 1 to 4 (p $<0.001)$.

\section{Apoptosis and Inflammation across CKD Stages}

According to our results, Bcl-2 expression was found to decrease significantly both in lymphocytes and monocytes as CKD stages were advancing $(\mathrm{p}<0.001$ and $\mathrm{p}<$ 0.04 , respectively; table 2). Conversely, sFas levels increased significantly ( $\mathrm{p}<0.001$ ), and so did serum levels of TNF- $\alpha$ and plasma levels of fibrinogen from CKD stage 1 to 4 ( $p<0.003$ and $p<0.001$, respectively). Serum levels of IL- 6 showed a trend to increase with the deterioration of renal function, while CRP, sFasL levels and annexin $\mathrm{V}$ staining did not change within CKD stages.

\section{Multivariate Analysis}

CKD remained the only independent predictor of $\mathrm{Bcl}-$ 2MMed levels, with CKD stage 4 patients having significantly lower levels compared to stage 1 and 2 patients (table 3). An eGFR $<60 \mathrm{ml} / \mathrm{min} / 1.73 \mathrm{~m}^{2}$, and serum albumin and CRP levels were found to predict Bcl-2LMed expression. sFas levels were significantly altered in CKD stages 
Table 2. Apoptosis and inflammation markers for all patients and across CKD stages

\begin{tabular}{|c|c|c|c|c|c|c|}
\hline & All patients & CKD 1 & CKD 2 & CKD 3 & CKD 4 & $\mathrm{p}$ \\
\hline Bcl-2LMed, molecules/cell & $1,579 \pm 44$ & $1,801 \pm 115$ & $1,799 \pm 97$ & $1,508 \pm 59$ & $1,356 \pm 81$ & $<0.001$ \\
\hline Bcl-2MMed, molecules/cell & $682(608-800)$ & $780(721-900)$ & $769(635-892)$ & $659(607-732)$ & $624(531-709)$ & $<0.04$ \\
\hline sFas, pg/ml & $10,900 \pm 275$ & $9,176 \pm 746$ & $8,542 \pm 369$ & $11,423 \pm 403$ & $13,462 \pm 461$ & $<0.001$ \\
\hline TNF- $\alpha, p g / m l$ & $1.97(1.4-4.4)$ & $1.43(0.9-1.98)$ & $1.68(1.3-2.5)$ & $1.9(1.4-2.7)$ & $2.8(1.9-3.5)$ & $<0.003$ \\
\hline Fibrinogen, mg/dl & $377(301-480)$ & $300(278-323)$ & $365(291-433)$ & $385(294-481)$ & $461(377-630)$ & $<0.001$ \\
\hline IL-6, pg/ml & $2.9(2.0-4.37)$ & $2.4(1.6-3.4)$ & $2.9(1.8-4.1)$ & $2.8(2.0-4.8)$ & $3.7(2.3-5.1)$ & NS \\
\hline $\mathrm{CRP}, \mathrm{mg} / \mathrm{l}$ & $2.0(0.9-4.4)$ & $1.6(0.6-2.9)$ & $2.2(1.0-5.0)$ & $2.6(1.0-5.8)$ & $2.0(0.5-4.2)$ & NS \\
\hline sFasL, pg/ml & $79 \pm 32$ & $72 \pm 23$ & $79 \pm 31$ & $80 \pm 34$ & $81 \pm 35$ & NS \\
\hline Annexin V-FITC+/PI-, \% & $12.6 \pm 8.6$ & $12.5 \pm 6.8$ & $14.9 \pm 9.1$ & $12.2 \pm 8.3$ & $10.7 \pm 8.9$ & NS \\
\hline
\end{tabular}

3 and 4 and from treatment with statin. TNF- $\alpha$ levels were significantly increased in CKD stages 2-4 and by IL-6 level. Regarding fibrinogen, an eGFR of $60 \mathrm{ml} / \mathrm{min} / 1.73 \mathrm{~m}^{2}$ was the threshold for significantly higher levels among CKD patients. Moreover, CRP and serum albumin significantly influenced plasma fibrinogen levels.

\section{Discussion}

In this study, we investigated levels of specific apoptotic and inflammatory markers across CKD stages 1-4. Interestingly, we were able to demonstrate that the majority of these alterations occurred early in the course of $\mathrm{CKD}$, as soon as patients entered stage 3 of CKD and even earlier. At the same time, we demonstrated that CKD remained a significant predictor for the aggregate of the assessed markers after adjusting for potential confounders.

Uremia has been linked to acquired immune deficien$\mathrm{cy}$, and dysregulation of apoptosis in leukocytes has been suggested as a regulatory pathway. Existing data suggest that enhanced apoptosis appears in the progression of CKD and uremic milieu per se is partly responsible for the phenomenon $[1-3,9,10]$. We demonstrated that expression of $\mathrm{Bcl}-2$ decreased significantly in the course of $\mathrm{CKD}$ which remained the only independent predictor. A change in Bcl-2 expression in vitro has been shown in predialysis and dialysis patients compared with healthy controls, which was linked with immune defects, but not with renal function $[3,11]$. The mechanism that leads to gradually lower $\mathrm{Bcl}-2$ expression in CKD as well as its clinical importance are poorly understood. It has been speculated that the diminished expression of $\mathrm{Bcl}-2$ is responsible for the failure of uremic lymphocytes to rescue from apoptosis by neglect [11].
The Fas/FasL system is a key regulatory apoptotic pathway. In our CKD population, sFas levels were significantly higher in patients with an $\mathrm{eGFR}<60 \mathrm{ml} / \mathrm{min} / 1.73 \mathrm{~m}^{2}$, possibly due to gradually decreasing renal clearance. In accordance to our results, Perianayagam et al. [10] observed a significant inverse correlation between sFas levels and creatinine clearance. Moreover, those of our patients who received statins had lower serum sFas levels compared with those who did not. Studies in populations with different cardiovascular risk factors and in uremic patients have shown that sFas concentrations are elevated, suggesting that $\mathrm{sFas}$ may be a novel marker of atherosclerotic vascular damage $[12,13]$. Furthermore, the ACTFAST study concluded that atorvastatin lowered sFas level mainly in patients with diabetes or metabolic syndrome through antiinflammatory effects on the vascular wall. These data are of particular interest considering that Fas/FasL interaction can induce the expression of proinflammatory cytokines implicated in the development of atherosclerosis [14]. Finally, regarding serum sFasL, we observed no significant correlation with renal function or with sFas, and a possible explanation could be that serum sFas may act as a protecting mechanism by binding circulating sFasL and thereby minimizing mediation of cellular apoptosis [10].

We noted gradually increasing levels of TNF- $\alpha$ and fibrinogen with progression of CKD. TNF- $\alpha$ is a key mediator of inflammation and plays a role in apoptosis as well. In animal models, its effects on kidneys include reduction of GFR and increase of albumin permeability, enhanced renal vasoconstriction and hypofiltration via reducing activity of NO [15]. Enhanced TNF- $\alpha$ level has been found in predialysis and dialysis patients compared to healthy controls [16], while two independent groups of investigators have shown an inverse correlation between renal function and TNF- $\alpha$ levels $[17,18]$. Several previous studies have demonstrated that increased production 
rather than reduced renal clearance is a primary cause of rising inflammatory cytokines including TNF- $\alpha$ [18]. Moreover, we found a significant positive correlation between TNF- $\alpha$ and IL- 6 serum levels, preserved after adjustment, which could possibly be explained by the reported 'cytokine network' in CKD [4].

Another finding of the present study was the gradual increment of plasma fibrinogen levels with eGFR $<60 \mathrm{ml} /$ $\min / 1.73 \mathrm{~m}^{2}$ being the threshold. Several studies have resulted in similar findings, while increased production has been suggested as the main pathophysiologic mechanism $[19,20]$. Moreover, recent epidemiological data have linked fibrinogen with incident CKD [21], and clinical evidence has suggested that fibrinogen is a risk factor for CKD progression to end stage possibly through the development of atherosclerosis and glomerulosclerosis [22].

In our study, the deterioration of CKD stage was associated with a marginal rise in serum IL- 6 and no change in CRP level, while other investigators have found strong negative correlation between IL- 6 and CRP levels with eGFR $[23,24]$. The discrepancy between the results might suggest that there is diversity in the expression of the inflammatory markers in the CKD population. Another possible explanation could be that CRP and IL- 6 levels fluctuate over time, being mainly influenced by comorbidity and subclinical infections; thus, continuous monitoring of these inflammatory markers is recommended as it provides more precise information on the 'real' inflammatory state [25].

Some limitations of this study should be considered. First, we did not include healthy controls as several previous studies have documented that apoptosis and inflammation are significantly higher in CKD patients compared to healthy controls. Second, our study was crosssectional in nature, which might be the most important limitation. However, the sufficient size of our non-dialysis study population, along with its distribution in all 4 CKD stages, ascribes to the study an advantage in comparison to previous similar studies.

\section{Conclusion}

Apoptosis appeared to increase across CKD stages, and this was associated with increased proinflammatory activity. CKD stage remained a significant predictor for most of the studied apoptotic and inflammatory markers. Further longitudinal studies are needed to clarify the complexity of interaction between apoptotic and inflammatory disorders in non-dialysis CKD patients.

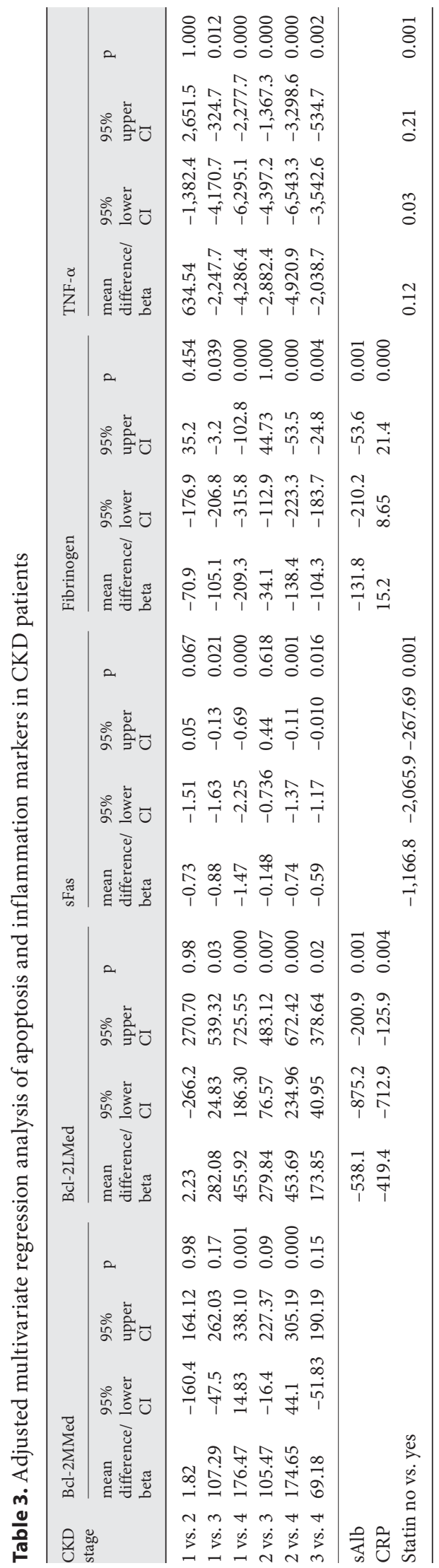




\section{Acknowledgements}

The authors thank Aleka Papageorgiou for her excellent secretarial assistance, and Dr. Vianda Stel, Department of Medical Informatics, Academic Medical Center, Amsterdam, for her statistical guidance.

\section{Disclosure Statement}

The authors state no conflict of interest and have no financial disclosures to report.

\section{References}

-1 Jaber BL, Cendoroglo M, Balakrishnan VS, Perianayagam MC, King AJ, Pereira BJ: Apoptosis of leukocytes: basic concepts and implications. Kidney Int 2001;59(suppl 78): S197-S205.

-2 Koliousi E, Vartholomatos G, Katopodis KP, Kolaitis N, Siamopoulos KC: Effect of the hemodialysis session on $\mathrm{Bcl}-2$ expression in peripheral blood mononuclear cells in vivo. Blood Purif 2006;24:542-547.

\3 Majewska E, Baj Z, Sulowska Z, Rysz J, Luciak M: Effects of uraemia and haemodialysis on neutrophil apoptosis and expression of apoptosis-related proteins. Nephrol Dial Transplant 2003;18:2582-2588.

4 Stenvinkel P, Ketteler M, Johnson RJ, Lindholm B, Pecoits-Filho R, Riella M, Urger HO, Cederholm T, Girndt M: IL-10, IL-6, and TNF- $\alpha$ : Central factors in the altered cytokine network of uremia - the good, the bad, and the ugly. Kidney Int 2005;67:1216-1233.

5 Stenvinkel P, Carrero JJ, Axelsson J, Lindholm B: Emerging biomarkers for evaluating cardiovascular risk in the chronic kidney disease patient: how do new pieces fit into the uremic puzzle? Clin J Am Soc Nephrol 2008; 3:505-521.

-6 Levey AS, Bosch JP, Lewis JB, Greene T, Rogers N, Roth D: A more accurate method to estimate glomerular filtration rate from serum creatinine: a new prediction equation. Modification of Diet in Renal Disease Study Group. Ann Intern Med 1999;130:461-470.

7 Iyer SB, Bishop JE, Abrams B, et al: Quantilbrite $^{\mathrm{TM}}$; A new standard for fluorescence quantititation. White paper. Scan Jose, Becton Dickinson Immunocytometry Systems, pl-16, part No 23-3496-00, 1997.

$\checkmark 8$ Vermes I, Haanen C, Steffen-Nakken H, Reutelingsperger C: A novel assay for apoptosis: flow cytometry detection of phoshatidylserine expression on early apoptotic cells using fluorescein labeled annexin V. J Immunol Methods 1995;184:39-51.

-9 Cendoroglo M, Jaber BL, Balakrishnan VS, Perianayagam MC, King AJ, Pereira BJG: Neutrophil apoptosis and dysfunction in uremia. J Am Soc Nephrol 1999;10:93-100.

-10 Perianayagam MC, Murray SL, Balakrishnan VS, Guo D, King AJ, Pereira BJ, Jaber BL: Serum soluble Fas (CD95) and Fas ligand profiles in chronic kidney disease. J Lab Clin Med 2000;136:320-327.
11 Fernández-Fresnedo G, Ramos MA, González-Pardo MC, de Francisco AL, LópezHoyos M, Arias M: B lymphopenia in uraemia is related to an accelerated in vitro apoptosis and dysfunction of Bcl-2. Nephrol Dial Transplant 2000;15:502-510.

12 Blanco-Colio LM, Martín-Ventura JL, de Teresa E, Farsang C, Gaw A, Gensini G, Leiter LA, Langer A, Martineau P, Hérnandez G, Egido J: ACTFAST investigators. Increased soluble Fas plasma levels in subjects at high cardiovascular risk: atorvastatin on inflammatory markers (AIM) study, a substudy of ACTFAST. Arterioscler Thromb Vasc Biol 2007;27:168-174.

13 Troyanov S, Hébert M-J, Masse M, Vigneault N, Sirois I, Madore F: Soluble Fas: a novel predictor of atherosclerosis in dialysis patients. Am J Kidney Dis 2003;41:1043-1051.

14 Schaub FJ, Han DK, Liles WC, Adams LD, Coats SA, Ramachandran RK, Seifert RA, Schwartz SM, Bowen-Pope DF: Fas/FADDmediated activation of a specific program of inflammatory gene expression in vascular smooth muscle cells. Nat Med 2000;6:790796.

15 Shahid M, Francis J, Majid DSA: Tumor necrosis factor- $\alpha$ induces renal vasoconstriction as well as natriuresis in mice. Am Physiol Renal Physiol 2008;295:F1836F1844.

16 Vaccaro F, Mule G, Cottone S, Giannitrapani L, Vadala A, Sparacino V, Calabrese S, Picone FP, Montalto G, Cerasola G: Circulating levels of adhesion molecules in chronic kidney disease correlate with the stage of renal disease and with C-reactive protein. Arch Med Res 2007;38:534-538.

17 Witko-Sarsat V, Friedlander M, Nguyen Khoa T, Capeillère-Blandin C, Nguyen AT, Canteloup S, Dayer JM, Jungers P, Drüeke T, Descamps-Latscha B: Advanced products as novel mediators of inflammation and monocyte activation in chronic renal failure. J Immunol 1998;161:2524-2532.
18 Descamps-Latscha B, Herbelin A, Nguyen AT, Roux-Lombard P, Zingraff J, Moynot A, Verger C, Dahmane D, de GrootellD, Jungers P, Dayert J-M: Balance between IL-1 $\beta$, TNF$\alpha$ and their specific inhibitors in chronic renal failure and maintenance dialysis. J Immunol 1995;154:882-892.

19 Landray MJ, Wheeler DC, Lip GY, Newman DJ, Blann AD, McGlynn FJ, Ball S, Townend JN, Baigent C: Inflammation, endothelial dysfunction, and platelet activation in patients with chronic kidney disease: The Chronic Renal Impairment in Birmingham (CRIB) Study. Am J Kidney Dis 2004;43: 244-253.

20 Singh D, Whooley MA, Ix JH, Ali S, Shlipak MG: Association of cystatin $\mathrm{C}$ and estimated GFR with inflammatory biomarkers: the Heart and Soul Study. Nephrol Dial Transplant 2007;22:1087-1092.

21 Bash LD, Erlinger TP, Coresh J, Marsh-Manzi J, Folsom AR, Astor BC: Inflammation, hemostasis, and the risk of kidney function decline in the atherosclerosis risk in communities (ARIC) study. Am J Kidney Dis 2009; 53:596-605.

22 Fried L, Solomon C, Shlipak M, Bleyer AJ, Chaves P, Furberg C, Kuller L, Newman A: Inflammatory and prothrombotic markers and the progression of renal disease in elderly individuals. J Am Soc Nephrol 2004;15: 3184-3191.

23 Bolton CH, Downs LG, Victory JG, Dwight JF, Tomson CR, Mackness MI, Pinkney JH: Endothelial dysfunction in chronic renal failure: roles of lipoprotein oxidation and pro-inflammatory cytokines. Nephrol Dial Transplant 2001;16:1189-1197.

24 Shlipak MG, Fried LF, Crump C, Bleyer AJ, Manolio TA, Tracy RP, Furberg CD, Psaty BM: Elevations of inflammatory and procoagulant biomarkers in elderly persons with renal insufficiency. Circulation 2003;107: 87-92.

25 Tsirpanlis G, Bagos P, Ioannou D, Bleta A, Marinou I, Lagouranis A, Chatzipanagiotou S, Nicolaou C: The variability and accurate assessment of microinflammation in hemodialysis patients. Nephrol Dial Transplant 2004;19:150-157. 